\title{
USURPATION AND DOMINANCE BEHAVIOR IN THE POLYGYNOUS SOCIAL WASP METAPOLYBIA CINGULATA (HYMENOPTERA: VESPIDAE: POLYBIINI) $^{1}$
}

\author{
By Adrian B. Forsyth \\ Museum of Comparative Zoology Laboratories, Harvard University, \\ Cambridge, Massachusetts 02138
}

\section{INTRODUCTION}

Usurpation is facultative intraspecific social parasitism. The term "usurpation" was first proposed by Yoshikawa ( 1955) to denote the process in which a female social insect invades a colony of the same species, kills or dominates the resident reproductive female and assumes her reproductive role. It has been postulated that usurpation behavior represents the first step in the evolution of the more advanced classes of interspecific social parasitism in wasps (Taylor, I939; Wilson, I97 I). However, usurpation behavior remains poorly studied relative to interspecific social parasitism and has been described in detail only twice (Janet, I903; Yoshikawa, 1955). Detection of usurpation requires the observation of marked colonies and this probably accounts for the paucity of data related to usurpation.

With reference to energy management, usurpation is an aggressive analogue of the cleptoparasitic reproductive strategy employed by many solitary wasps, flies, and scarab beetles. The usurping queen gains a nest and often a worker force to aid in rearing her own offspring. Hence there is an obvious selective advantage to usurpation which is presumably opposed by the probability of being killed by the resident queen or worker wasps. However, it is not clear what the stimuli involved in illiciting usurpation actually are. The loss of a nest or the failure to gain the alpha position in a dominance hierarchy are obvious possibilities.

Previous observations of usurpation have not included data on the prior behavior of the usurping females and have been confined to temperate monogynous species. There have been no reports of usurpation or social parasitism in polygynous wasps such as the Polybiini in spite of an a priori higher expectation of cheating and deception in polygynous systems relative to monogynous systems.

\footnotetext{
1Published with the aid of a grant from the Museum of Comparative Zoology.

Manuscript received by the editor November 25, 1975.
} 
Moreover, dominance behavior has been poorly studied in polygynous wasps. Herein, a set of observations on an instance of usurpation in a tropical polygynous wasp, Metapolybia cingulata (Hymenoptera: Vespidae: Polybiini) and the dominance interactions that preceded usurpation seem worthy of a separate presentation.

\section{Materials ANd Methods}

The observations presented here were made during a three month study of Metapolybia cingulata in western Ecuador.

A group of colonies were modified to permit close observation and were marked for identification in the manner described by Forsyth (1976). The two colonies discussed in this report were relatively small and young. Colony $\mathrm{C}$ initially contained 27 adults and a comb area of I IO $\times 85 \mathrm{~mm}$. Colony $\mathrm{F}$ initially contained 55 adults and a comb area of $\mathrm{I} 2 \mathrm{O} \times 8 \mathrm{O} \mathrm{mm}$. On the basis of cell reusage, colony $\mathrm{F}$ was older than colony $\mathrm{C}$.

Metapolybia cingulata, like most polybiines, lacks strongly differentiated morphological castes, and it is usually necessary to dissect females to conclusively distinguish workers from queens (Richards and Richards, 195I). However, there are differences in queen and worker behavior which allows one to categorize individuals; for example, workers groom queens but not each other. The observations presented here were derived from a continuing long term study in which the reproductive roles were inferred behaviorally rather than by dissection.

\section{OBSERVATIONS}

Strong dominance interactions were first observed in colony $\mathrm{C}$ on June 28. Two females were involved which are designated DDT and YA. DDT was a young female which had eclosed on June 20. YA had been present in the colony since the initiation of the study on May 23. DDT was very attractive to the workers who frequently groomed her, particularly about the abdomen. YA was much less frequently groomed, but clearly occupied a dominant role. She frequently postured in the aggressive wing-spread position and was often the recipient of trophallaxis.

On June 28 I observed YA approach DDT and grab with her forelegs the head of DDT. DDT broke the hold and moved away. Shortly after, while DDT was being groomed, YA again approached and attempted to bite the abdomen of DDT. DDT responded with an abdominal stinging motion (sting retracted) but was physically 
knocked from the nest by YA. After DDT returned, aggressive interactions of similar nature were again initiated by YA, but these were not successful in displacing DDT.

There were two basic forms of aggressive contact. In the milder form, both individuals stood grasping each other face to face with their abdomens pointing towards each other and would vigorously antennate each other. In more extreme interactions, YA would attempt to bite the abdomen of DDT, who would make stinging motions and then break away.

On June 29 YA was absent from the nest. Colony $\mathrm{C}$ was exchanging workers with other colonies at this time (Forsyth, 1976). However, YA was not present at any of these colonies and after several days was presumed dead. DDT was behaving in a queenlike manner, being the only wasp receiving extensive grooming and trophallactic donations.

On July 3 a routine check of colony $F$ revealed the presence of YA. This was unexpected as colony $\mathrm{F}$ was not exchanging workers with colony $\mathrm{A}$ and non-interchanging colonies are generally hostile to foreign wasps. At this time, YA was behaving as a worker sitting quietly on the comb and regurgitating when solicited.

YA subsequently became more active working on the comb. By July 6, YA was exhibiting wing-spreading behavior. On July 7 th, I found an individual from colony $B$ with one wing chewed in two. Dissection revealed this to be a young reproductive female. YA was very active and aggressive. YA continued to be a resident in colony F until July 13. Shortly after this, colonies $\mathrm{C}$ and $\mathrm{F}$ were destroyed by nearby construction work. Dissection of some wasps salvaged from colony $\mathrm{B}$ revealed at least one reproductive female to be present.

\section{Discussion}

One interpretation of these observations is that the failure of an older queen (YA) to dominate a younger reproductive (DDT) led it to abandon colony $\mathrm{C}$, invade colony $\mathrm{F}$ and displace one of the resident queens.

Metapolybia cingulata is known to exchange workers between related colonies (Forsyth, 1976). However, in this instance a noninterchanging and presumably unrelated colony was the object of usurpation. In unrelated colonies the invading female should be opposed by not only the resident queen, but also by the workers who will "prefer" to rear related offspring. Clearly, there is some subtle deception process involved in this particular usurpation. In a small 
monogynous system such as Polistes, usurpation may be accomplished by simple mechanical domination of both workers and reproductives by the invading female. In this case, in which there are many resident workers, usurpation cannot proceed simply by aggression. It is probable that the invasion is accomplished by deception based on colony odor. The usurping female was not at either colony for several days. This may have allowed loss of colony odor and facilitated her acceptance into the colony.

The dominance behavior and aggression described previously may have broader significance than simply the triggering of usurpation. Inter-queen competition appears to be pronounced in small colonies to the extent that it may alter the social structure. Most small Metapolybia cingulata colonies rapidly become effectively monogynous (Forsyth, in prep.). Eberhard (I973) has reported this phenomenon in $M$. docilis and $M$. aztecoides. She found that monogyny was produced by worker persecution of all reproductive females but one. My observations suggest that monogyny in small colonies may also be the result of inter-queen aggression. Polygyny develops when colonies become large (Forsyth, in prep.). In a proximate sense, the occurrence of many reproductive females in the large colonies may simply reflect the ineffectiveness of dominance in large colonies. In an evolutionary context, the importance of inter-queen dominance will vary as a function of colony level selection pressures and inbreeding, a relationship yet to be quantified in the field.

\section{AcKnowledgements}

I would like to thank Harvard University for financial support, Dr. E. O. Wilson for helpful suggestions and Ken Miyata and Richard Webster for assistance in the field.

\section{Literature Cited}

EBERHARD, M. J. W.

1973. Monogyny in "polygynous" social wasps. Proc. VII Cong. IUSSI, London, pp. 396-403.

Forsyth, A. B.

1976. Interchange between colonies of the social wasp Metapolybia cingulata (Hymenoptera: Vespidae: Polybiini). Behavioral Ecol-

JANET, C. ogy and Sociobiology [Submitted].

1903. Observations sur les guepes. C. Naud, Paris. 85 pp.

Richards, O. W. AND M. RichaRds.

1951. Observations on the social wasps of South America (Hymenoptera: Vespidae). Trans. Roy. Entomol. Soc. London 102: 1-167. 
TAYLOR, L. H.

1939. Observations on social parasitism in the genus Vespula. Ann. Entomol. Soc. Amer. 32: 304-315.

WILson, E. O.

1971. The Insect Societies. Belknap Press of Harvard Univ. Press, Yoshikawa, K. Cambridge, Mass. 548 pp.

1955. A polistine colony usurped by a foreign queen: ecological studies of Polistes wasps II. Insectes Sociaux 2: 255-260.

NOTE ON BITTACUS VALIDUS IN BALTIC AMBER. In my reviews of Tertiary Mecoptera (I93I, I954), I expressed doube that Bittacus validus, preserved in Baltic amber and described by Hagen in 1856 , was actually a mecopteron. Recently, Dr. Hermann Jaeger, of the Paläontologisches Museum (Humboldt-Universität) in Berlin, sent me Hagen's type specimen for study. It turns out to be a caddisfly, showing clearly the characteristic mouthparts, hairy wings, and looped anal veins. Unfortunately, other structural features are so poorly preserved in the specimen that generic determination within the Trichoptera will probably prove impossible. For the present, at any rate, it seems advisable to list the insect as (Trichopteron) validus Hagen. [Reference: Carpenter, F. M., I931, Journ. N. Y. Ent. Soc., 39: 412; 1954, Psyche, 6I: 36. Hagen, H. A., I 856 , Berendt, Bernst. befindl. organ. reste vorw., 2( ( ) :9г ] - F. M. Carpenter, Harvard University. 

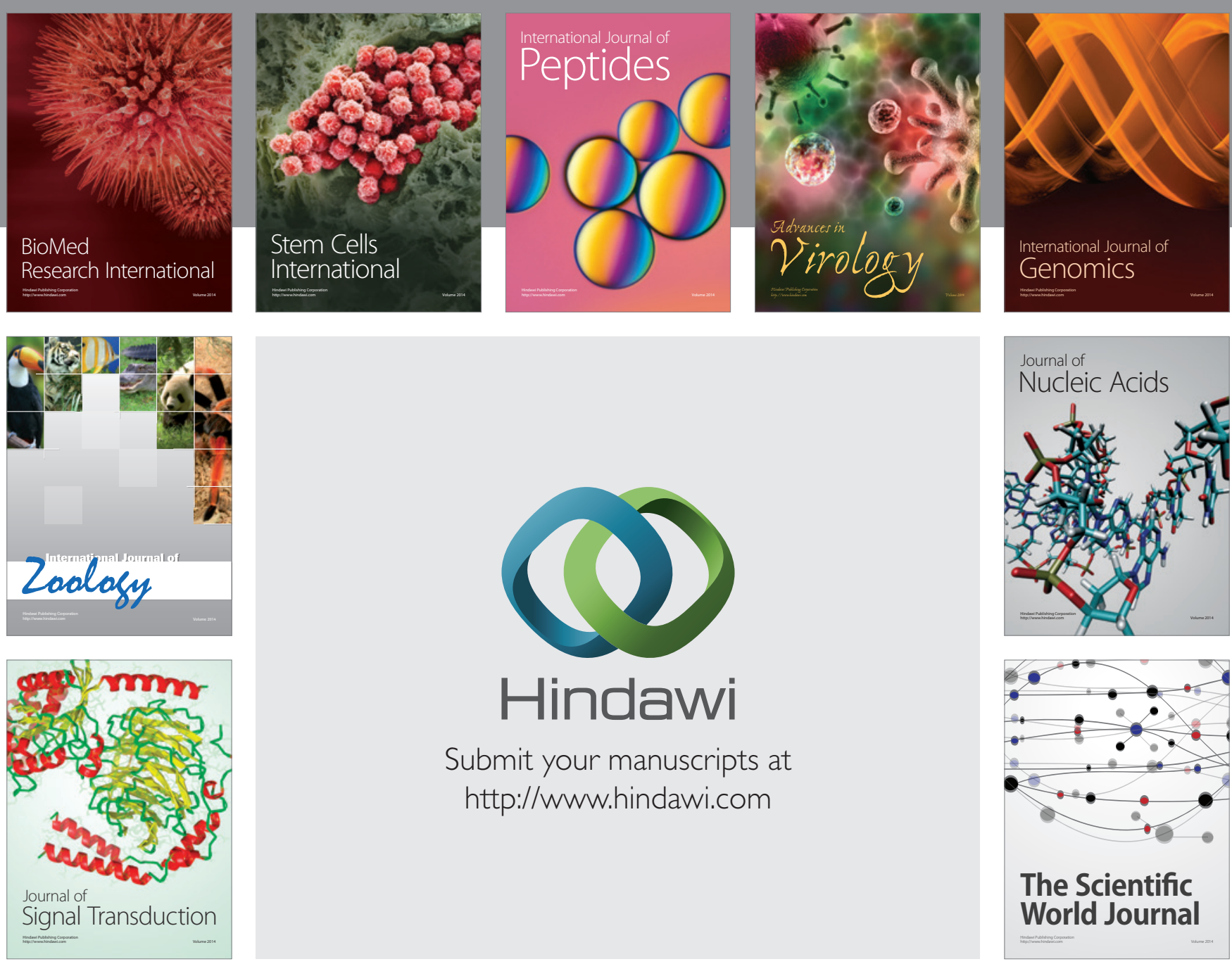

Submit your manuscripts at

http://www.hindawi.com
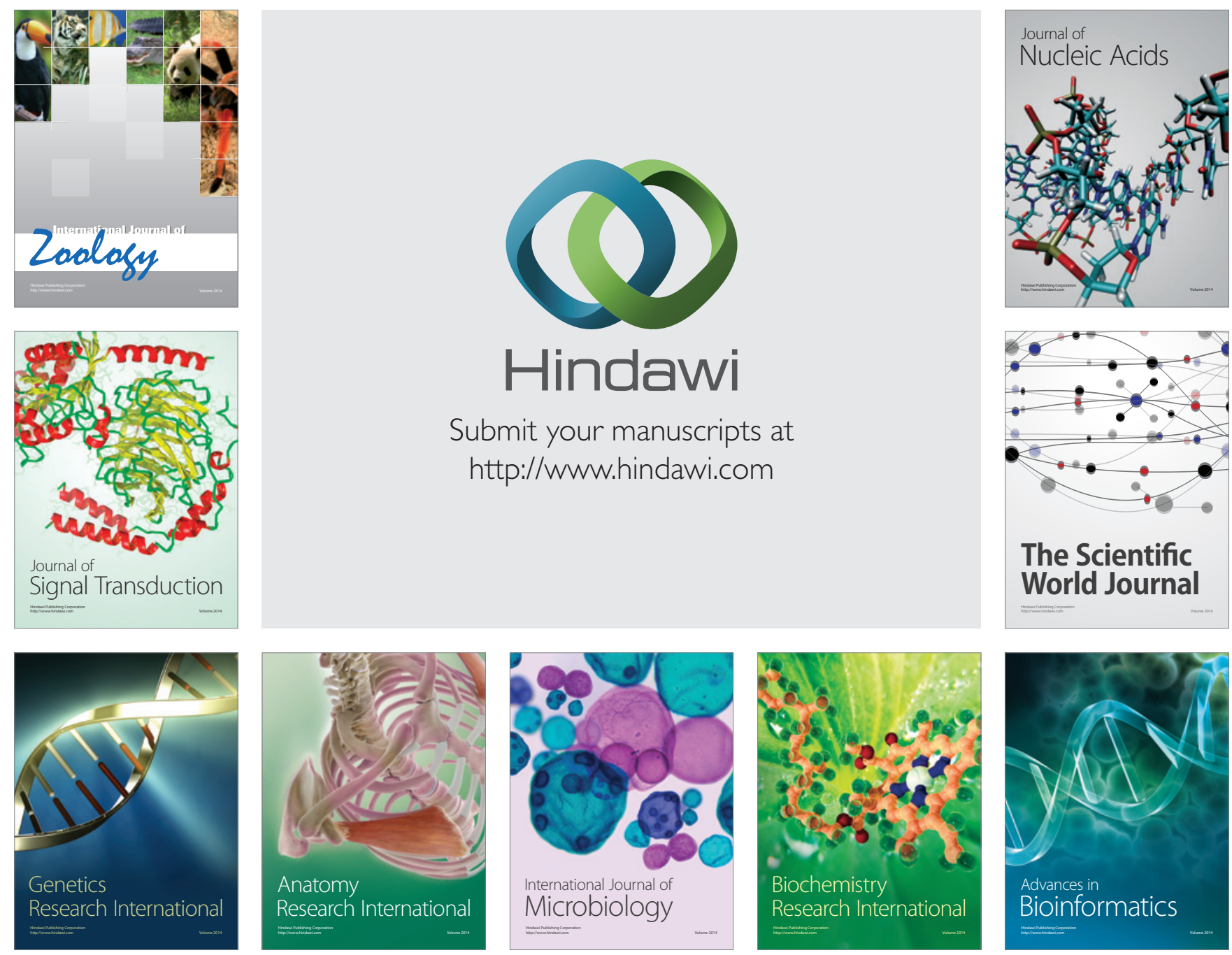

The Scientific World Journal
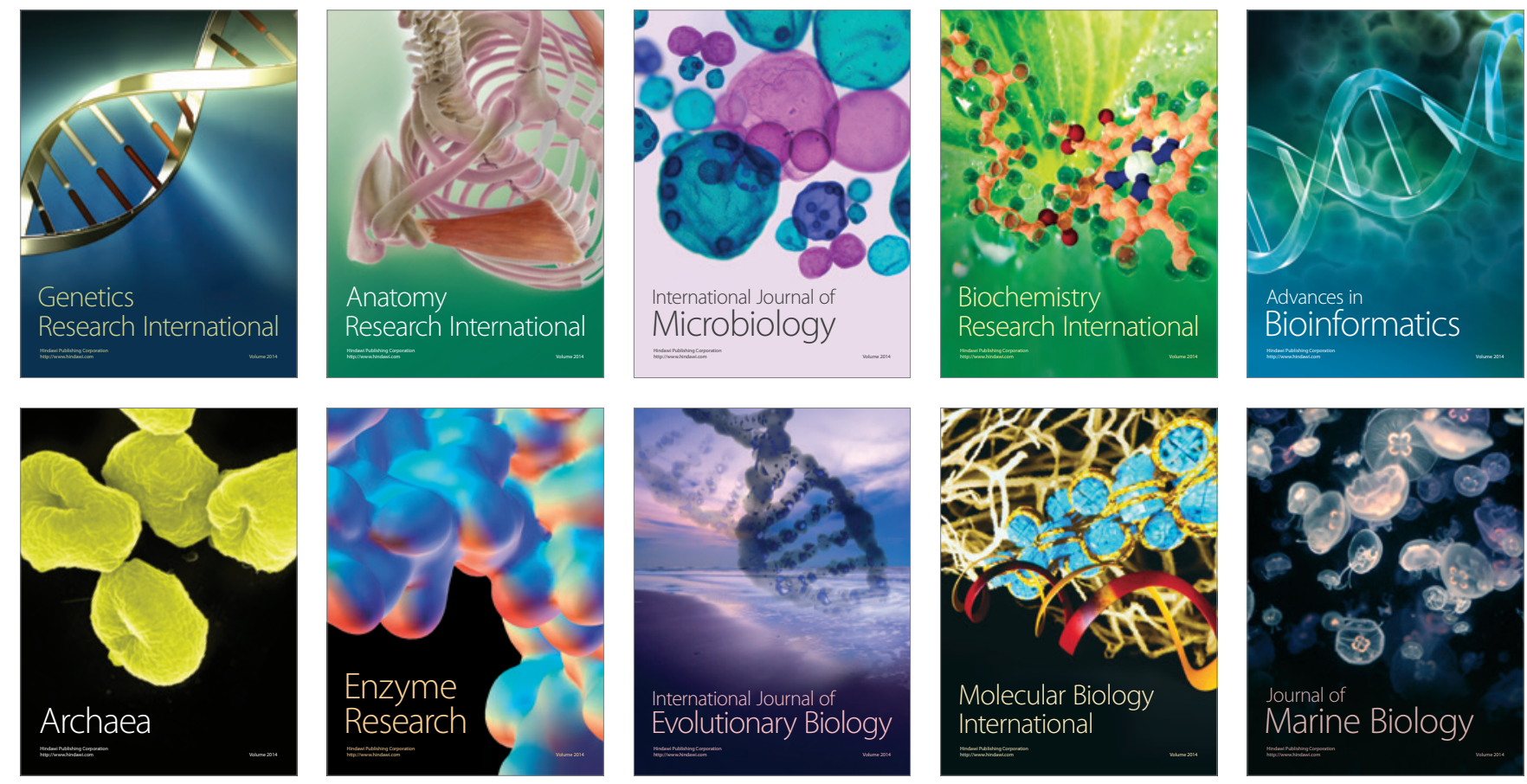